\title{
Automated system for the calibration of magnetometers
}

\author{
Petrucha, Vojtech; Kaspar, Petr; Ripka, Pavel; Merayo, José M.G.
}

Published in:

Journal of Applied Physics

Link to article, DOI:

$10.1063 / 1.3062961$

Publication date:

2009

Document Version

Publisher's PDF, also known as Version of record

Link back to DTU Orbit

Citation (APA):

Petrucha, V., Kaspar, P., Ripka, P., \& Merayo, J. M. G. (2009). Automated system for the calibration of magnetometers. Journal of Applied Physics, 105(7), 07E704. https://doi.org/10.1063/1.3062961

\section{General rights}

Copyright and moral rights for the publications made accessible in the public portal are retained by the authors and/or other copyright owners and it is a condition of accessing publications that users recognise and abide by the legal requirements associated with these rights.

- Users may download and print one copy of any publication from the public portal for the purpose of private study or research.

- You may not further distribute the material or use it for any profit-making activity or commercial gain

- You may freely distribute the URL identifying the publication in the public portal

If you believe that this document breaches copyright please contact us providing details, and we will remove access to the work immediately and investigate your claim 


\title{
Automated system for the calibration of magnetometers
}

\author{
Vojtech Petrucha, ${ }^{1, a)}$ Petr Kaspar, ${ }^{1, b)}$ Pavel Ripka, ${ }^{1, c)}$ and Jose M. G. Merayo ${ }^{2, d)}$ \\ ${ }^{1}$ Department of Measurement, Faculty of Electrical Engineering, Czech Technical University in Prague, \\ Technicka 2, 16627 Praha 6, Czech Republic \\ ${ }^{2}$ National Space Institute-DTU Space, Technical University of Denmark, Elektrovej 327, 2800 Kgs. Lyngby, \\ Denmark
}

(Presented 12 November 2008; received 10 October 2008; accepted 29 October 2008; published online 6 February 2009)

\begin{abstract}
A completely nonmagnetic calibration platform has been developed and constructed at DTU Space (Technical University of Denmark). It is intended for on-site scalar calibration of high-precise fluxgate magnetometers. An enhanced version of the same platform is being built at the Czech Technical University. There are three axes of rotation in this design (compared to two axes in the previous version). The addition of the third axis allows us to calibrate more complex devices. An electronic compass based on a vector fluxgate magnetometer and micro electro mechanical systems (MEMS) accelerometer is one example. The new platform can also be used to evaluate the parameters of the compass in all possible variations in azimuth, pitch, and roll. The system is based on piezoelectric motors, which are placed on a platform made of aluminum, brass, plastic, and glass. Position sensing is accomplished through custom-made optical incremental sensors. The system is controlled by a microcontroller, which executes commands from a computer. The properties of the system as well as calibration and measurement results will be presented. (C) 2009 American Institute of Physics. [DOI: 10.1063/1.3062961]
\end{abstract}

\section{INTRODUCTION}

The idea of a calibration platform comes from a similar project, which was carried out at the National Space Institute of the Technical University of Denmark. The purpose of that project was to build a system for a scalar calibration and testing of high precise (space grade) fluxgate sensors and magnetometers. Scalar calibration of three-axial vector magnetometer is based on positioning of the magnetometer in homogeneous magnetic field. The collected data set should contain enough readings, which are equally distributed in all directions. From these data the nine parameters can be calculated: sensitivities and offsets of individual sensors and the angular deviations between them. The calculation is made by iterative procedure, which minimizes the variation in the scalar value $B$ (with a linear least-squares estimator used). ${ }^{1}$ The ideally measured $B$ is constant for every direction. This is achieved by using correction matrices, which can contain the mentioned nine correction parameters. In every iteration step the new values of these corrections are calculated until required precision is reached. The limitations of the mentioned calibration methods include nonhomogeneity of the calibration field, magnetic contamination, Earth's field variation, stability of the position during measurement, and nonlinearity of the sensors.

There are two possibilities how to achieve the mentioned positioning: either the magnetometer is fixed in a precise

\footnotetext{
${ }^{\text {a) }}$ Author to whom correspondence should be addressed. Electronic mail: petruv1@fel.cvut.cz. Tel.: +420224 353 964. FAX:+420233339929.

${ }^{b)}$ Electronic mail: kaspar@fel.cvut.cz. Tel.: +420 224352188.

${ }^{c)}$ Electronic mail: ripka@fel.cvut.cz. Tel.: +420 224353 945. URL: www.maglab.cz.

${ }^{d)}$ Electronic mail: jmgm@space.dtu.dk. Tel.: +45 45253452. FAX: +454588 7133. URL: www.space.dtu.dk
}

three-axial calibration system and the artificial field is rotated by proper adjusting of the currents into the calibration coils. Another possibility is to move the magnetometer in the Earth's field using a nonmagnetic positioning platform. The first approach is limited to few special laboratories, which have to be thermostated and periodically calibrated by another complicated procedure. This approach is thus usually limited for testing and calibration of the finalized instruments or complete satellites. The second approach is more convenient for the testing and calibrations during development of new devices. A platform with two axes of freedom (pitch and roll) is sufficient for this application. The only requirement is to place the axis of pitch rotation perpendicularly to the vector of Earth's magnetic field. Then by setting the pitch and roll we can reach arbitrary direction with respect to the Earth's field and thus get all the samples needed to uniformly cover an imaginary unit sphere.

The calibration and testing of navigation systems (e.g., compass modules) at the Czech Technical University was the motivation for continuing to work on that project. Strapdown compass module ${ }^{2}$ developed at the CTU comprises of a vector fluxgate magnetometer and vector MEMS accelerometer. The calibration of such a compass module is a more complicated task. Scalar calibration of the magnetometer and accelerometer is the first step. In this step we get the mentioned nine coefficients for each vector instrument. Two axes of rotation are still enough for this step. Afterwards a mutual position of the magnetometer and accelerometer with respect to the reference frame has to be calibrated. For this we have to rotate the device in the following sequence: rotation in azimuth (while roll and pitch are fixed), then in pitch (while azimuth and roll are fixed), and finally in roll (with azimuth and pitch fixed). Three independent axes of rotation are 


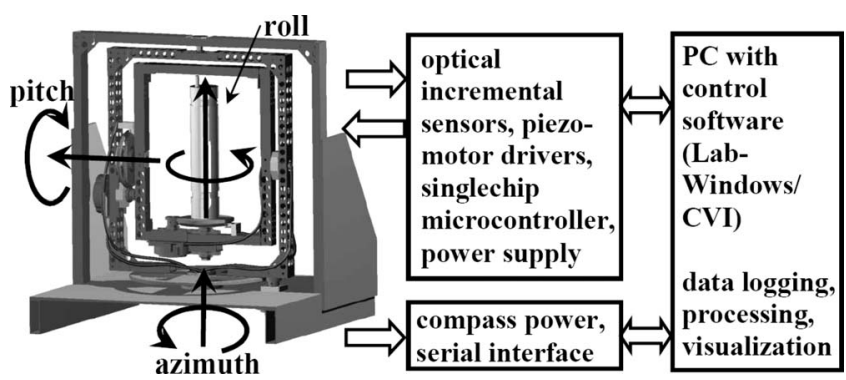

FIG. 1. Block diagram of the nonmagnetic calibration platform.

needed for this step. Very important is the rigidity of the platform, mutual perpendicularity of the axes, and the uniformity of the data acquisition, while the absolute positioning precision is not critical. Such procedures can be performed even during the Earth's field perturbations, ${ }^{3}$ however, the field monitoring by Overhauser magnetometer is desirable.

The same platform can be used to check the accuracy of azimuth measurement of the calibrated compass. The azimuth should stay constant for each value of azimuth, while the roll and pitch are changed (roll in the range of $\pm 180^{\circ}$, pitch in the range of approximately $\pm 75^{\circ}$ - the azimuth loses its meaning for pitch values close to $90^{\circ}$ ). In order to check the absolute azimuth accuracy (or linearity), a device with higher resolution of position setting is needed (the target accuracy of our strapdown compass is $0.2^{\circ}$, which requires $0.1^{\circ}$ precision of the inclination).

Until now we have used a nonmagnetic theodolite. The drawback of this device is a limited range of available position setting (pitch approximately $\pm 60^{\circ}$ ); it is not absolutely nonmagnetic and the hand operation is inaccurate, inconvenient, and time consuming. Other method of positioning (for scalar calibration only) is a "free hand" method where the device under test is manipulated by hand, and data are collected during a slow smooth motion. This method is fast and no special equipment is needed but it brings dynamic errors into the process (irregularity of the motion, vibrations). The calibration platform, which is introduced in this paper has three axes of freedom (independent setting of yaw, pitch, and roll), it is fully nonmagnetic and motorized (allows computer controlled operation).

\section{SYSTEM CONCEPTION}

The system can be divided into three main parts (see Fig. 1). The mechanical part is basically a gimbaled platformone fixed frame that holds two rotating frames and a rotating center support. Each of them is driven by a piezoelectric motor. Three incremental optical sensors are used to sense the position of the frames and to control the motors in a closed loop. An electronic control unit consists of a singlechip microcontroller, which receives the commands from a computer (via USB interface), evaluates the signals from the incremental sensors, and controls dedicated piezoelectric motor drivers. The whole system is controlled by a personal computer via an application with a simple graphical user interface.

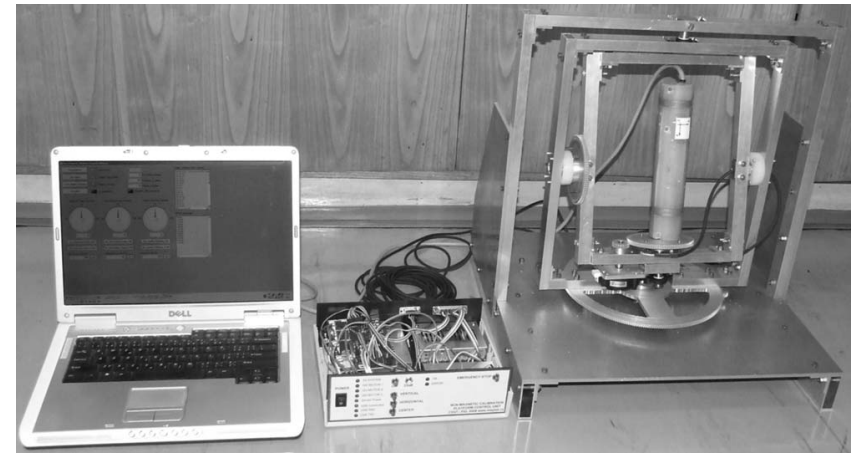

FIG. 2. Calibration platform with control unit and compass module.

\section{PLATFORM DESIGN}

The ShinSei's USR60 piezoelectric motors are the most powerful nonmagnetic motors available on the market. However their $1 \mathrm{Nm}$ maximum torque is insufficient and gearing was necessary. Aluminum tooth wheels with gearing ratios of 1:4 and 1:10 (for the outer vertical frame) were used. The frames are made of aluminum profiles, which are lightened by drilling as many holes as possible (while the frame has to stay rigid). In order to bring down the friction, plastic bearings with glass balls were used instead of a plastic friction bearing. The wiring of the motor and sensor cables goes through the axes of rotation in order not to significantly limit the range of motion. There are no brakes needed; the piezoelectric motors have sufficient static momentum.

The angular position is measured by incremental optical sensors. Only $1^{\circ}$ resolution is required, but the magnetic cleanliness should be very high, as these sensors are very close to the devices under test. We found no really nonmagnetic optical incremental sensor on the market. Thus the sensors were custom built using a code wheel made of a printed circuit board. The problem is a contamination of most electronic components with ferromagnetic materials. Even small surface mount device (SMD) parts represent serious problem. Therefore there are only SMD infrared light emitting diodes and phototransistors (GL100MN and PT100MF) in the vicinity of the device under test. All other circuits are placed several meters away from the platform.

The electronic control unit is based on the ATMEL AVR microcontroller (ATMEGA128). The personal computer (PC) user interface is written in National Instruments LabWindows/CVI programming environment (Fig. 2).

\section{RESULTS}

The three-axial platform development is in the testing phase. We present results of scalar calibration of the vector MEMS accelerometer. Raw data and corrected data are shown in Fig. 3. The rms variance of the gravity scalar value is $14.65 \mathrm{mg}$ before correction and $1.73 \mathrm{mg}$ after the calibration constants are applied. Compared with similar data taken during a smooth slow motion (hand driven) - raw data are $18.37 \mathrm{mg}$ and corrected data $10.56 \mathrm{mg}$. It is evident that the errors caused by motion irregularity are suppressed. Other benefits are the increased speed of the calibration, repeatabil- 


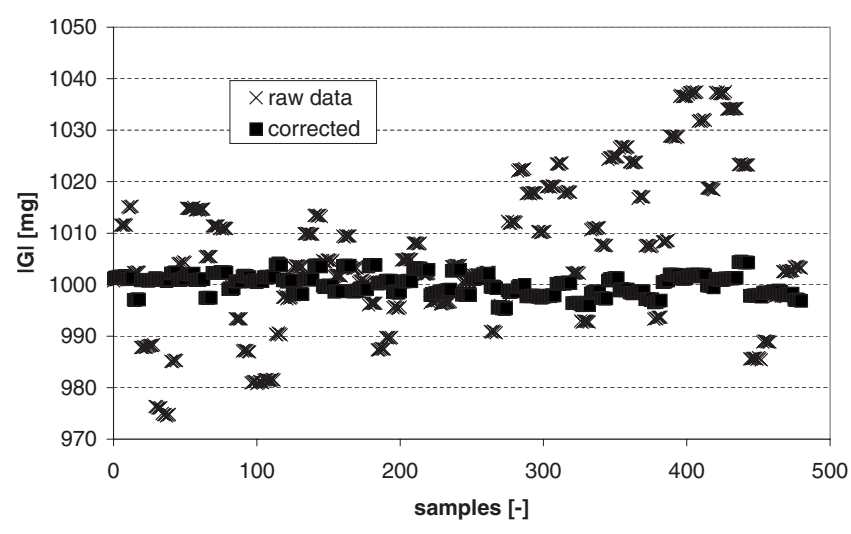

FIG. 3. MEMS accelerometer calibration results.

ity, and the possibility to create a map of residuals, which can detect some systematic errors such as nonlinearity or cross-field errors.

\section{CONCLUSION}

The parameters of the system are summarized in Table I. One of the most important parameters is a magnetic cleanliness. The fluxgate vector magnetometer used in the compass module has a resolution far better than $1 \mathrm{nT}$ and therefore the
TABLE I. Summary of calibration platform parameters.
Projected sensor dimensions

Maximum sensor weight

Degrees of freedom

Positioning precision

Positioning stability

Rotation speed (pitch, roll)

Rotation speed (azimuth)

Range of motion

Projected magnetic cleanliness

Power requirements

Total weight

$100 \times 100 \times 300 \mathrm{~mm}^{3}$
$0.75 \mathrm{~kg}$
3
$1^{\circ}$
$\sim 0^{\circ} / 1 \mathrm{~min}$
$30^{\circ} / 1 \mathrm{~s}$
$15^{\circ} / 1 \mathrm{~s}$
$\pm 360^{\circ}$

$<.05 \mathrm{nT}$ in the sensor area

$25 \mathrm{~W}$

$\sim 12 \mathrm{~kg}$ level of influence of ferromagnetic components has to be safely below this level. The piezoelectric motors are specified as nonmagnetic but our measurements show that there is a small amount of ferromagnetic material present (magnetic field change about $0.5 \mathrm{nT}$ at $50 \mathrm{~mm}$ distance). This limits the present achievable accuracy. We will try to evaluate and suppress this influence.

${ }^{1}$ J. M. G. Merayo, P. Brauer, F. Primdahl, J. R. Petersen, and O. V. Nielsen, Meas. Sci. Technol. 11, 120 (2000).

${ }^{2}$ J. Vcelak, V. Petrucha, and P. Kaspar, Sens. Lett. 5, 279 (2007).

${ }^{3}$ J.-H. Wang and G. Yang, Meas. Sci. Technol. 17, 153 (2006). 